\title{
The Effects of Cold Violence in Workplace and the Governance Mechanism \\ Yu-Ting LI
}

\author{
Department of Business Administration, Jincheng College, Sichuan University, Chengdu, Sichuan \\ Province, China \\ twozi779368927@qq.com
}

Keywords: Workplace Cold Violence, Influence Outcome, Governance Mechanism.

\begin{abstract}
Workplace cold violence is a non-physical contact type mental injury derived from interpersonal deviations such as workplace abuse, workplace bullying and workplace exclusion. This paper summarizes the concept and causes of cold violence in the workplace, analyzes the impact of the psychological and behavioral aspects of the staff, and puts forward the governance mechanism.
\end{abstract}

\section{Introduction}

In recent years, with the workplace cold violence intensified to the staff in interpersonal and spiritual level caused a lot of negative impact, and further lead to the increase in turnover rate, the decline in efficiency and other results. These issues need to be reformed from macroeconomic policy aspects to micro-personal self-regulation.

\section{The Concept of Workplace Cold Violence}

" Workplace cold violence" by "workplace abuse" and "bullying" and "workplace exclusion" and other relevant behavior derived from a form of expression, the "cold violence" from the leadership, colleagues, subordinates and clients of a non-physical contact type, continued to show exclusion, neglect, and indifference to others, which makes others physically and mentally harmed.

\section{The Cause of Cold Violence in the Workplace Analysis}

\section{Organizational Factors}

Organizational aspects of organizational culture values of the lack of organizational procedures unfair and work factors led to the workplace cold violence. In a non-benign organization, employees feel less respected and recognized, and at the same time work pressure cannot be resolved, gradually evolve into cold workplace violence.

\section{Group Factors}

The group has three factors: leadership, colleagues and clients. Leadership styles, colleagues' personalities and 'circle' culture, and unfair behavior of customers can lead to cold violence in the workplace.

\section{Personal Factors}

Staff sex, length of service, personality characteristics and other factors can also lead to cold workplace violence. For example, some scholars have found that employees who often produce negative emotions are more likely to be subjected to cold violence in the workplace, and will also pass on such negative emotions to others, and sometimes become "perpetrators".

\section{Workplace Cold Violent Influence Result}

According to the research of many scholars, the influence of workplace cold violence on employees 
is mostly negative. It is mainly divided into the attitude level and behavior level of employees.

\section{The Influence of Workplace Cold Violence on Employees' Attitudes}

\section{The Impact on Employee Turnover Intention}

Tepper (2000) suggests that abusive management is related to turnover intention; Kelly and Schepman (2006) argue that employees tend to have a tendency to leave their jobs after they have been excluded from work. Ferris (2008) found that there was a significant positive correlation between workplace exclusion and turnover intention. LU Hong (2010) found that disruptive leadership had a significant negative influence on the loyalty, responsibility and job satisfaction of subordinates, and had a significant positive predictive effect on the turnover intention and job stress of subordinates.

\section{The Impact on Employee Organizational Commitment}

Becker (1960) put forward the concept of "organizational commitment", it is seen as the employee with the increase of investment and the organization had to continue to stay in the organization of a psychological, reflect a psychological contract between employee and organization. Dr. Wang (2000) believes that organizational commitment comes from employees' recognition of organizational goals, resulting in a certain attitude or behavior.

Allen and Meyer (1990) study shows that workplace ostracism will reduce the employee's organization commitment; Williams (2007) that will not only workplace ostracism on the individual's sense of belonging, self-esteem, sense of control to the outside world and the significance of the survival of the psychological needs of a threat, but also cause a variety of individual employees many negative emotions for example, excessive depression, anxiety, anger and sadness and so on, which have a negative impact on individual mental health.

\section{On the Work of Employees and the Attitude of Life}

Tepper (2000) shows that workplace abuse is positively related to employee work - family life conflict, and is negatively correlated with employee's life satisfaction. Hoobler and Brass (2006) found that job abuse would affect whether employees were engaged in domestic violence.

Aryee and so found that cold violence in the workplace through the organization of fair factors (interpersonal interaction is not fair) to affect the emotional commitment, the workplace cold violence will reduce the staff of the organization's emotional attachment and recognition.

Many employees in the company by the "cold violence", at home will be this negative emotions into impatience, irritability, etc., and even this kind of emotions into action, vent to their families, resulting in "domestic violence" and so on The At the same time, this increase in cold violence will reduce the degree of social civilization, the formation of a negative social atmosphere.

\section{The Impact of Cold Violence on the Behavior of Employees}

\section{On the Performance of Staff Performance}

Harris KJ; Kacmar K M and Zivnuska S. (2007) found that the relationship between abusive supervision and employee self-evaluation and managerial performance was negatively correlated, and the strength of the relationship depends on whether employees perceive their work as valuable.

Gao Riguang (2009) found that abusive management was significantly positively correlated with employee performance and its peripheral performance, and that organizational citizenship was partly mediated between employee performance and abusive management, between abusive management and peripheral performance Complete mediation.

Guo Lei (2010) studies show that abusive supervision and team performance was negatively correlated, team efficacy exists intermediary role between management and team performance in the abuse of shame, and the uncertainty of business environment in abuse supervision and fill in between the sense of efficacy regulation.

Dong Yuechao (2011) found that the use of social exchange theory proved that if subordinates suffer abusive management of subordinates, then subordinates who suffer abusive management will 
give supervisors negative feedback, such as reducing job performance.

Li Yuhui, Wang Zhen and Huang Canwei (2016) the results of the study found that abusive supervision has a significant positive effect on psychological distress, has a significant negative effect on job performance; psychological distress mediates the abusive relationship between management and job performance; psychological capital regulation abuse management effect on psychological distress, psychological capital the higher abuse supervision positive effect on psychological pain is weak.

\section{On the Impact of Employee Workplace Deviations}

There is also a negative behavior for employees who are exposed to cold violence in the workplace, and the universality and importance of such acts have attracted the attention of many scholars. It is described as antisocial behavior, misconduct, non-compliance Behavior and workplace deviations.

Robinson (1995) employee workplace deviance (workplace deviance) refers to the members of the organization of spontaneous behavior, and this behavior is a violation of the norms of the organization, policy and system, and the threat to the organization or the organization member's benefits, specific performance: sabotage, theft, corruption, late, colleagues abuse, slander spreading rumors and sexual harassment.

Robinson (1998) suggests that inappropriate interpersonal interaction may lead to employee deviant behavior. Ashforth (1997) abusive supervision leads to a sense of frustration. Frustration and unfairness can lead to employee's deviant behavior, so we can see that workplace cold violence has a great influence on employee deviant behavior.

Vandenbo and Lind (2002) put forward the theory of uncertainty management, which can explain the motivation of workplace deviant behavior when employees encounter abusive management. After employees suffer from abusive management, they tend to lose control of their emotions, so they show negative reactions to the organization to improve their self-control.

Vandenbo and Lind (2002) put forward the theory of uncertainty management, which can explain the motivation of workplace deviant behavior when employees encounter abusive supervision. After employees suffer from abusive management, they tend to lose control of their emotions, so they show negative reactions to the organization to improve their self-control.

Rahim et al. (2008) suggest that organizational contextual factors that influence employee deviance can include organizational support, organizational justice, organizational climate, organizational policies, and the type of leader.

To sum up, this study suggests that a comprehensive model of workplace cold violence is shown below:

Table 1 Workplace cold violence comprehensive research model

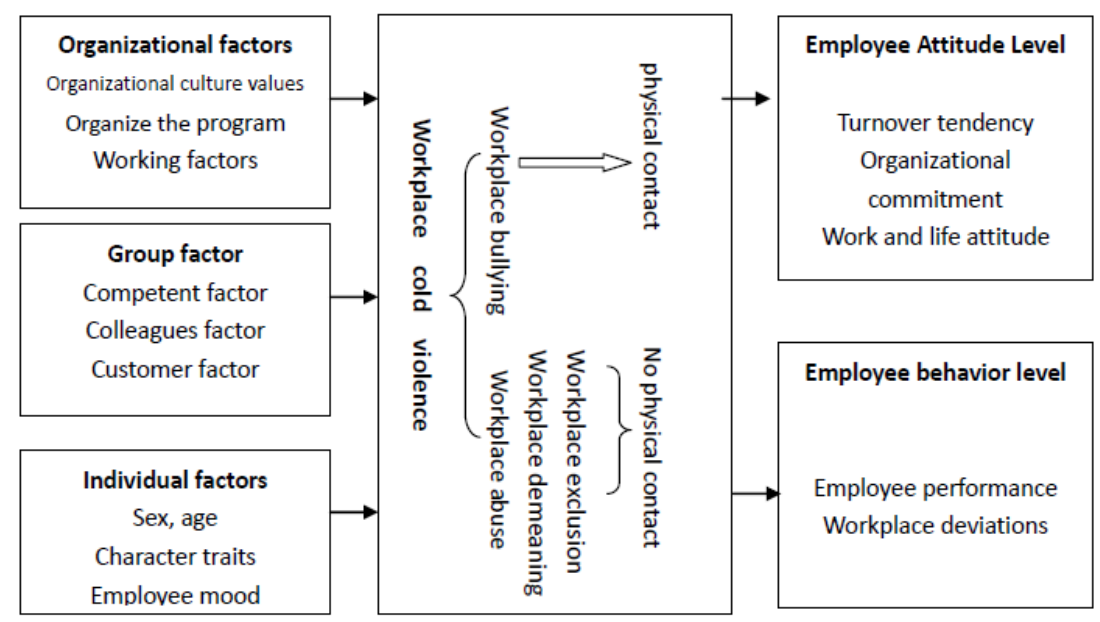




\section{The Workplace Cold Violence Governance Mechanism}

\section{Based on China's National Conditions of the Governance Mechanism}

According to Hofstedt's six cultural dimensions of cross-cultural research, we can see that: Chinese employees are very important to the rights, which leads us to enlarge the image of the leadership in the mind, and then if the leadership has "; By the impact of traditional culture, Chinese employees usually think that collectivism is higher than individualism, and sometimes there are employees in the "workplace cold violence", "the workplace is cold and violence" and so on, many employees are not directly against; "Behavior, even if it is not related to the staff, it is difficult not to join the number of party" circle ", which will cause" workplace cold violence "behavior intensified; Since ancient times by the" patriarchal " The impact of women are often vulnerable groups in the workplace, in the workplace is more vulnerable to workplace cold violence.

\section{The Development of Chinese Culture}

The definition of the word "person" in Chinese traditional culture is "benevolent, people", that must be the word "two" can be defined, more shows that Chinese between "human touch" is a kind of interrelated things. Chinese has been known to be considerate and warmhearted person, to draw a line between is ready to help others rather than with relatives and friends, so we must carry forward the human society, reduce the "cold" phenomenon, the transformation to the workplace level becomes reduced indifferent interpersonal relationship; at the same time, The Analects of Confucius mentioned in " Do unto others as you would be done" also reminds us, do not stand, the interaction between people should respect each other first.

\section{Civil Moral Quality Requirements}

At the eighteen meeting of China in 2013, the general secretary once again proposed to comprehensively build up the moral quality of our citizens. After improving the citizen's moral quality, we should start a balance between the moral orientation and the utilitarian orientation. With the start of the balance trend, performance in the workplace for employees not only interest, pay more attention to the relationship between morality and reduce employee because position, salary, welfare gap and cause the alienation phenomenon.

\section{Social Inclusion}

Social tolerance implementation of each person is actually good, mentioned in the Mencius - LLA: "Learn to use the strengths of others to perfect yourself. It is to do good with others" Be kind to others and be kind to yourself.

\section{The Organizational Level of Governance Mechanisms}

\section{Build a Healthy Organizational Culture}

Enterprises should establish a positive corporate culture. Harmony of the cultural atmosphere to bring employees not only a good working environment, but also a sense of belonging the sense of belonging in the enterprise is like the same in the family. This kind of emotion brings the "sense of security" to the staff so that the staff can be more fully put into the work, and can be more sensible and friendly in interpersonal communication to deal with.

\section{Enhance Organizational Fairness}

The fairness of the organization has a great influence on the psychological level and the behavior level of the employees. Once the staff feel the organization is not fair, it is easy to produce negative emotions caused by psychological harm, and sometimes cannot be resolved is likely to be transformed into someone else's cold violence. Improve the fairness of the organization, not only in terms of performance, pay, but also to break the traditional Chinese "be promoted according to status"the unspoken rules, so that employees feel the psychological justice. 


\section{Increase the Transparency of Enterprise Management}

Enterprises should first increase the transparency of the system, pay information, so that employees understand the dominant system of enterprises, which can increase the staff cohesion, a sense of fairness, while promoting mutual supervision within the enterprise to promote the optimization of enterprise management processes.

\section{Organize More Activities}

Enterprises through the organization activities can enhance the mutual understanding of employees, creating a relaxed working atmosphere, so that employees from the tension in the release of interpersonal relationships, creating a sense of teamwork, but also can reduce interpersonal conflicts.

\section{Organizational values Construction}

Changes in the core values are first formed in the leadership, and then by layer, gradually change the original beliefs of employees. The enterprise should develop a plan of action, which includes communication strategies, action steps, schedules and means of assessing progress.

\section{The Governance Mechanism at the Group Level}

\section{Employee Relationship Management}

With the Help of Expert Team Power.

Employee relationship management is very complex, knowledge and skills related to economic, social, cultural, technical, psychological and other areas, companies can make use of external experts to realize the mechanism of communication and staff, understand employee status timely, resolve the employees in interpersonal communication problems encountered.

\section{Construct Employee Satisfaction Questionnaire.}

By providing employee satisfaction questionnaire, this platform regularly understands the difficulties of employees in their work and interpersonal relationships, and finds and solves them in a timely manner.

\section{Strengthen Labor Relations Management.}

In the management of labor relations in enterprises, should establish the fair and comprehensive rules and regulations, colleagues let employees participate in the democratic management, let employees better and superiors, colleagues and customers communicate, reduce misunderstanding.

\section{Labor Dispute Mediation Committee.}

Labor dispute mediation committee of labor dispute adjustment of a mass autonomous activities, employees and enterprises through this platform can better solve the contradictions in work or interpersonal relationship.

\section{Establishment of Employee Complaint Mechanism.}

The perfect employee appeal system can obtain the employee's trust and support, and in the face of the problems of work and interpersonal communication, employees can protect their rights through the complaint mechanism.

\section{Give Full Play to the Role of Workers' Congresses.}

Staff congress system through the participation of organizations, participation in the post and individual participation in three aspects, so that the three parties to better understand each other's needs, and can better construct organizational structure. 


\section{Customer Relationship Management}

\section{In Customer Management, We Should Increase Customer Retention, Customer Satisfaction} and Customer Loyalty.

In the company, we must first establish the concept of customer relationship management, establish and improve customer management system.

\section{Establishing the "Blacklist" System of Customers.}

For employees who intend to harm their employees, they should be pulled into the "blacklist" of their clients to protect their rights and physical and mental health.

\section{The Governance Mechanism at the Individual Level}

\section{Assess Employees' Values}

Enterprises should increase the value of the assessment of employees during the recruitment of the assessment of the project, through the evaluation of the results of the analysis, from the beginning did not employ values and corporate culture does not match the people. Regular assessment of the value of employees, values are changing with the development of internal and external environment and improve.

\section{Improve Self-Decompression, the Ability to Actively Integrate}

Employees should learn to resolve the pressure in the face of cold violence when the situation do not give up on themselves, but should take the initiative to face the problem, the individual staff, pay attention to cultivate their own active personality, in the face of this indifference, neglect should be more active To think about the solution, jump out of interpersonal indifference circle.

\section{Improve the Boss's Personal Qualities}

As a boss on the one hand to continue to strengthen the party's policy of learning, improve the political theory of quality; the other hand, to optimize their own leadership style, more fair and objective, standing on the overall consideration.

\section{Conclusion}

This paper briefly introduces the concept and causes of "cold violence in the workplace" in the research results of a large number of outstanding scholars in the early stage, analyzes its influence and governance mechanism, and forms a comprehensive research model of cold violence in the workplace. There are many immature, hope that more scholars can pay attention to the workplace cold violence and participate in the extension of governance mechanisms to explore.

\section{References}

[1] Bennett J. Tepper Abusive Supervision in Work Organizations: Review, Synthesis, and Research Agenda 2007, 33 (3) :261-289

[2] Tepper B J. Consequences of Abusive Supervision [J]. Academy of Management Journal, 2000, 43(2):178-190.

[3] Kelly K M, Schepman S. Language exclusion and consequences of perceived ostracism in the workplace [J]. Group Dynamics Theory Research \& Practice, 2006, 10(1):56-70.

[4] Ferris D L, Brown D J, Berry J W, et al. The development and validation of the Workplace Ostracism Scale [J]. Chinese Journal of Clinical Psychology, 2008, 93(6):1348-66.

[5] Darja MaslićSeršić. Further Assessment of Meyer and Allen's Three-Component Model of Organizational Commitment: Croatian Data [J]. Bundesgesundheitsblatt - Gesundheitsforschung Gesundheitsschutz, 1999, volume 11(6):1-9. 
[6] Williams K D. Ostracism - Annual Review of Psychology, 2007 58(1):425[J]. Annual Review of Psychology.

[7] Tepper B J. Consequences of Abusive Supervision [J]. Academy of Management Journal, 2000, 43(2):178-190.

[8] Hoobler J M, Brass D J. Abusive supervision and family undermining as displaced aggression [J]. Journal of Applied Psychology, 2006, 91(5):1125-33.

[9] Aryee S. Antecedents and Outcomes of Work-Family Conflict among Married Professional Women: Evidence from Singapore [J]. Human Relations, 1992, 45(8):813-837.

[10] Harris K J, Kacmar K M, Zivnuska S. An investigation of abusive supervision as a predictor of performance and the meaning of work as a moderator of the relationship [J]. Leadership Quarterly, 2007, 18(3):252-263.

[11] Gao Riguang. Destructive leadership will be organized an evil member of the herd destructive leadership behavior? -- A Study on [J]. Management in the context of the world China organization, 2009 (9): 124-132.

[12] Li Yuhui, Wang Zhen, Huang Canwei, et al. The impact of abusive management on employees' psychological pain and job performance: a mediating model that is regulated, [J]. management review, 2016, 28 (2): 127-137.

[13] Robinson, Sandra L, Bennett, Rebecca J. A typology of deviant workplace behaviors: A multdimensiona[J].Academy of Management Journal,1995,38(2):555-573.

[14] Rahim A R A, Nasurdin A M. Trust in organizational and workplace deviant behaviour[J]. Gadjah Mada International Journal of Business, 2008, 81(1):1-4.

[15] Robinson S L, Greenberg J. Employees behaving badly: Dimensions, determinants and dilemmas in the study of workplace deviance.[C]// C L Cooper \& D M Rousseau, Trends in Organizational Behavior. 1998.

[16] Ashforth B E. Petty Tyranny in Organizations: A Preliminary Examination of Antecedents and Consequences [J]. Canadian Journal of Administrative Sciences / Revue Canadienne des Sciences de l'Administration, 1997, 14(2):126-140.

[17] Kees V D B, Lind E A. Uncertainty management by means of fairness judgments.[J]. Advances in Experimental Social Psychology, 2002, 34(34):1-60.

[18] Mitchell M S, Ambrose M L. Abusive supervision and workplace deviance and the moderating effects of negative reciprocity beliefs [J]. Journal of Applied Psychology, 2007, 92(4):1159-68.

[19] Tepper B J, Duffy M K, Hoobler J, et al. Moderators of the Relationships Between Coworkers' Organizational Citizenship Behavior and Fellow Employees' Attitudes.[J]. Journal of Applied Psychology, 2004, 89(3):455. 